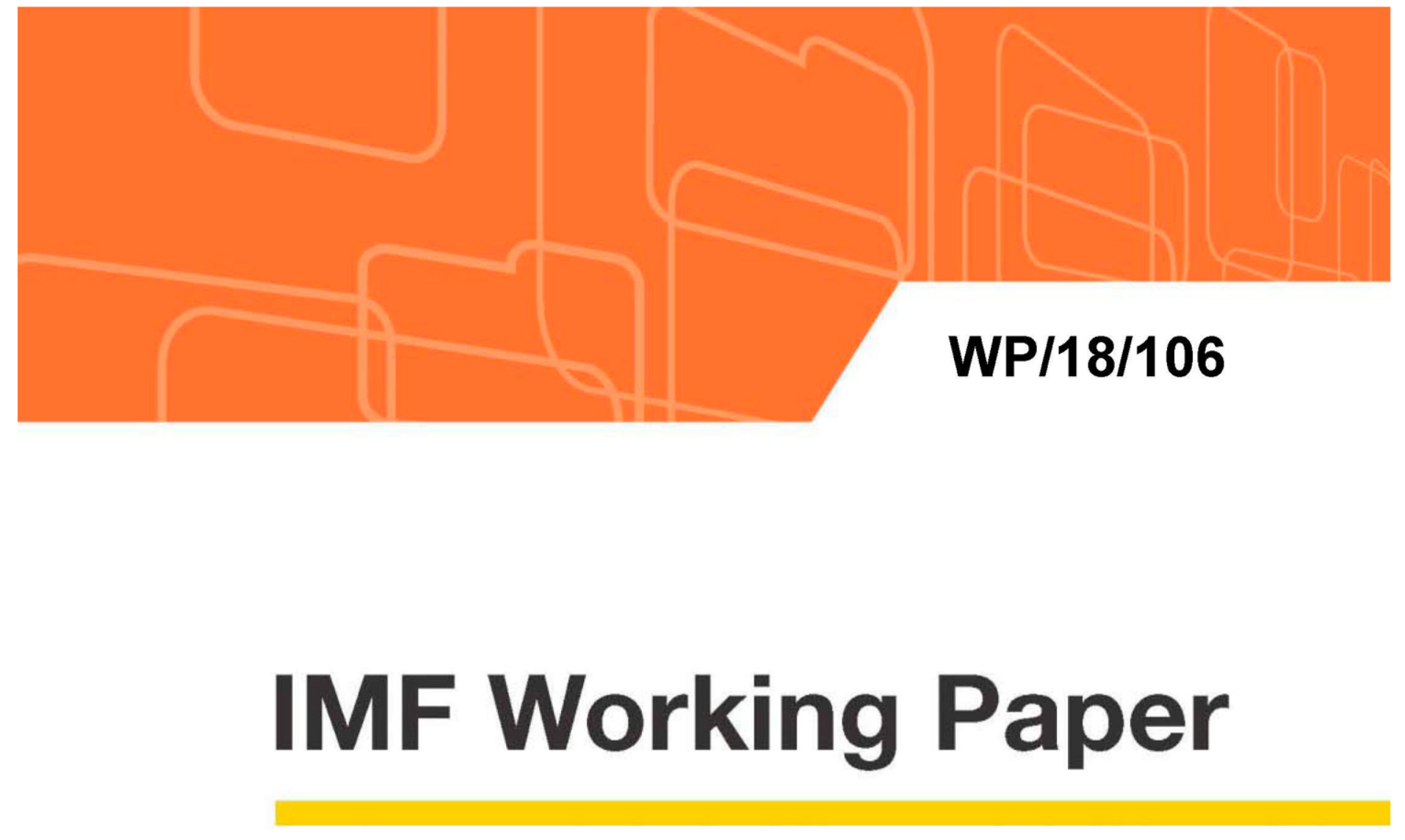

\title{
Explaining Inflation in Colombia: A Disaggregated Phillips Curve Approach
}

by Sergi Lanau, Adrian Robles, and Frederik Toscani

IMF Working Papers describe research in progress by the author(s) and are published to elicit comments and to encourage debate. The views expressed in IMF Working Papers are those of the author(s) and do not necessarily represent the views of the IMF, its Executive Board, or IMF management. 


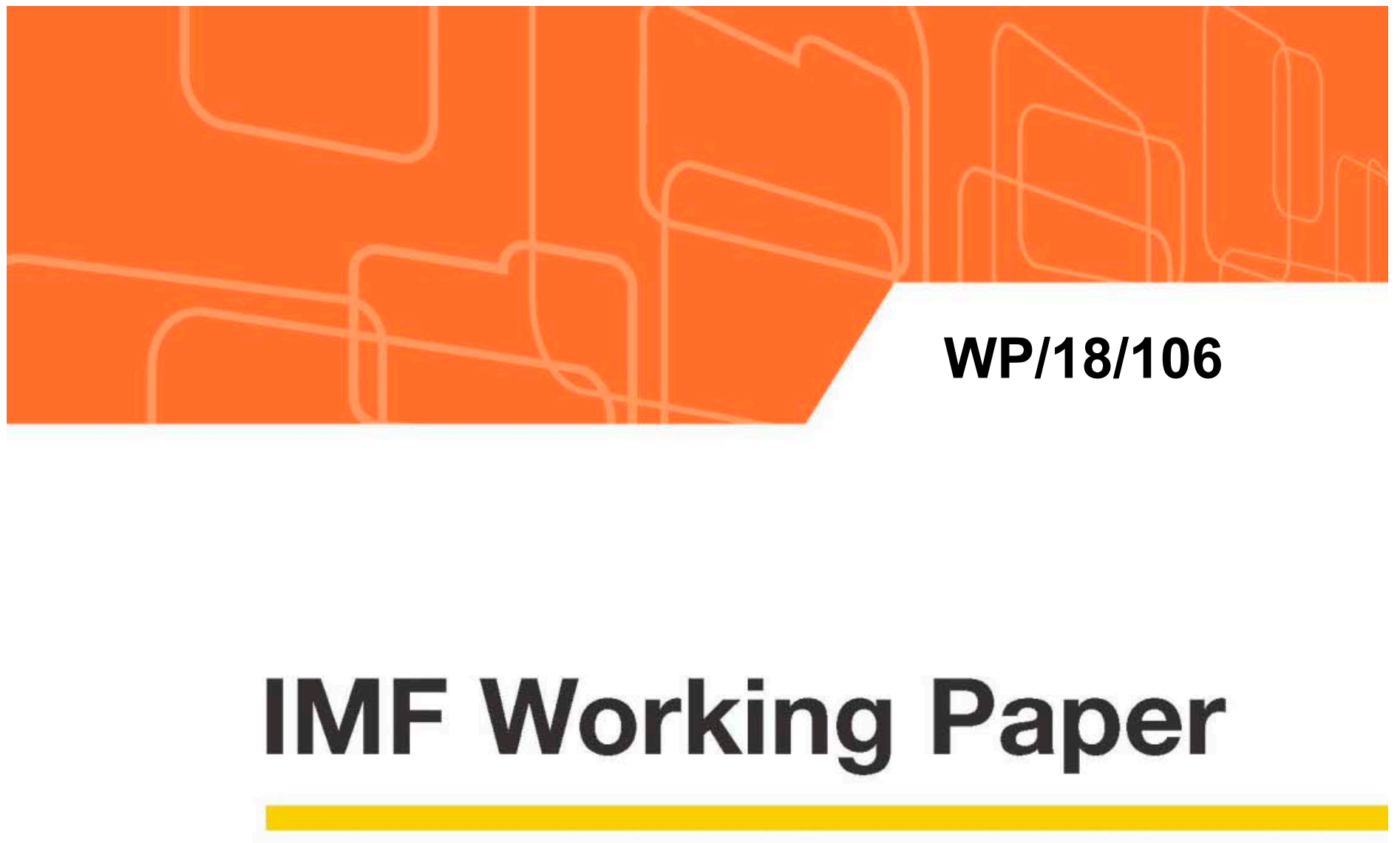

\section{Explaining Inflation in Colombia: A Disaggregated Phillips Curve Approach}

by Sergi Lanau, Adrian Robles, and Frederik Toscani

IMF Working Papers describe research in progress by the author(s) and are published to elicit comments and to encourage debate. The views expressed in IMF Working Papers are those of the author(s) and do not necessarily represent the views of the IMF, its Executive Board, or IMF management. 


\title{
IMF Working Paper
}

Western Hemisphere Department

\section{Explaining Inflation in Colombia: A Disaggregated Phillips Curve Approach Prepared by Sergi Lanau, Adrian Robles, and Frederik Toscani}

Authorized for distribution by Jorge Roldós

May 2018

\section{IMF Working Papers describe research in progress by the author(s) and are published to elicit comments and to encourage debate. The views expressed in IMF Working Papers are those of the author(s) and do not necessarily represent the views of the IMF, its Executive Board, or IMF management.}

\begin{abstract}
We study inflation dynamics in Colombia using a bottom-up Phillips curve approach. This allows us to capture the different drivers of individual inflation components. We find that the Phillips curve is relatively flat in Colombia but steeper than recent estimates for the U.S. Supply side shocks play an important role for tradable and food prices, while indexation dynamics are important for non-tradable goods. We show that besides allowing for a more detailed understanding of inflation drivers, the bottom-up approach also improves on an aggregate Phillips curve in terms of forecasting ability. In the baseline forecast scenario, both headline and core inflation converge towards the Central Bank's inflation target of 3 percent by end-2018 but these favorable inflation dynamics are vulnerable to large supply shocks.
\end{abstract}

JEL Classification Numbers: E31, E37

Keywords: Inflation Components, Phillips Curve, Forecast, Colombia

Author's E-Mail Address: slanau@imf.org; arobles@,imf.org; ftoscani@imf.org 


$\begin{array}{lr}\text { ABSTRACT } & \underline{1} \\ \text { I. INTRODUCTION } & \underline{3} \\ \text { II. BACKGROUND AND RECENT DEVELOPMENTS } & \underline{4} \\ \text { III. METHODOLOGY } & \underline{8} \\ \text { IV. UNDERSTANDING INFLATION USING PHILLIPS CURVES } & \underline{11} \\ \quad \text { A. Top-Down Analysis of Headline and Core Inflation } & \underline{16} \\ \text { B. A Bottom-Up Approach } & \underline{19} \\ \text { V. FORECASTING INFLATION USING PHILLIPS CURVES } & \underline{19} \\ \quad \text { A. Model Evaluation: Pseudo Out-of-Sample Forecasts } & \underline{21} \\ \quad \text { B. Model Evaluation: Residuals } & \underline{21} \\ \text { C. Inflation Forecasts } & \underline{24} \\ \text { VI. CONCLUSION } & \end{array}$

\section{FIGURES}

1. Key Components of CPI Basket___ $\underline{5}$

2. Volatility of Tradable and Non-tradable Inflation _ $\underline{5}$

3. Components of Non-Tradable Inflation __ 7

4. Components of Regulated Prices __ 7

5. Scatter Plots of Output and Unemployment Gap against Headline and Core $\_\_\underline{8}$

6. Reaction of Inflation to one Percentage Point Increase in Output Gap ___ 14

7. Real Minimum Wage Increases ___ 16

8. Reaction of Tradable Inflation to one Percentage Point Increase in Key __ 17

9. Inflation of Education Costs in Latin America ___

10. Pseudo-out-of-Sample Forecast Performance__ 19

11. Pseudo-out-of-Sample Forecast Performance by Component __ 20

12. Pseudo-out-of-Sample Forecast Performance by Component __ 21

13. Baseline Inflation Forecast for 2018

14. Tradable and Non-tradable Inflation Forecast for 2018

15. Forecast Scenarios _ 23

\section{TABLES}

1. Headline Inflation Specification

2. Core Inflation Specification _ـ 13

3. Phillips Curve in Colombia___

\section{ANNEX}

I. Tables and Charts 


\section{INTRODUCTION}

Among a backdrop of low global inflation, much work has been devoted to explaining and decomposing the driving forces of falling inflation, with a consistent result being that a secular downward trend in tradable goods inflation has been a key driver for this circumstance (see, for example, IMF World Economic Outlook October 2016). Work for advanced economies has also stressed an apparent flattening of domestic Phillips curves in the context of globalization (Mark Carney, 2017). ${ }^{1}$

The downward trend in headline inflation also holds true for most emerging markets, with improved monetary policy frameworks as well as global factors likely contributing to the structural improvement. Cyclically, many Latin American countries, among them Colombia, have experienced high volatility of inflation over the past few years, as currency depreciations and food shocks have pushed inflation up, while increasing economic slack worked to lower inflation.

In this context, it is worthwhile to re-examine the Phillips curve relationship. In particular, we follow work by Matheson (2006) and Abdih et. al (2016) among others, and take a bottom-up approach where we estimate individual Phillips curves for the key components of CPI inflation. ${ }^{2}$ Different components of the CPI basket have displayed very different dynamics in Colombia recently and we want to understand the drivers of these occurrences in more detail. Specifically, we decompose the CPI basket into tradables, non-tradables, food and regulated prices. Non-tradables and regulated prices are in turn again decomposed into education, rent and other for the former, and fuel, transportation and public services for the latter.

Our general framework for modelling inflation follows the triangular model of the Phillips curve set out by Gordon (see, among others, Gordon, 2011). ${ }^{3}$ The model is 'triangular' because it captures the three main drivers of inflation (i) inertia; (ii) demand shocks proxied by unemployment or the output gap; and (iii) explicit supply-side shocks.

Mirroring the results of Bryan and Meyer (2010) for the U.S. and the ones by Julio et al. (2017) for Colombia, we find that prices of tradables (which are more flexible than those of non-tradables) react more strongly to economic slack than non-tradable prices. We also find

\footnotetext{
${ }^{1}$ [De]Globalisation and inflation. Speech given by Mark Carney, Governor of the Bank of England 2017 IMF Michel Camdessus Central Banking Lecture 18 September 2017.

${ }^{2}$ Besides the large literature on the Phillips curve, our paper is also related to the literature which emphasizes differences in price setting across different product categories. For Colombia, Julio et al. (2010) use data from over 12 million price reports to develop stylized facts on price setting and find substantial heterogeneity. Bunn and Ellis (2012) for the U.K. study highly disaggregated micro data at the individual product level and again find evidence for large heterogeneities in price setting behavior. Aron et al. (2014) study disaggregated price dynamics in South Africa and find large heterogeneities in the response to exchange rate movements across categories and across individual products.

${ }^{3}$ An important early paper taking a careful look at the Phillips curve in Colombia is Lopes and Misas (1999) who take a similar approach to us.
} 
an important role for supply-side shocks in the bottom-up Phillips curves. Weather shocks, exchange rate movements, international price movements, and the VAT hike all have important impacts on inflation, particularly on tradable and food inflation. Rent and education inflation are strongly influenced by inertia and indexation. Regulated prices behave according to their own processes, with fuel broadly tracking Gulf of Mexico gasoline prices, for example. As stressed in the literature, long-term (24 month) inflation expectations are important for determining inflation. In terms of the aggregate relationship between economic slack and inflation, we find a relatively flat Phillips curve but steeper than the recent estimate for the U.S. by Abdih et al. (2016) and steeper than the average slope in a sample of 20 advanced countries estimated by Blanchard et al. (2015).

We show that our estimations (both top-down and bottom-up) significantly improve on simple autoregressive processes and that the bottom-up approach has additional explanatory power over the former. Using our estimated Phillips curves to forecast inflation in Colombia, we find that in the baseline scenario which employs growth, exchange rate and other variables taken from the IMF World Economic Outlook database, headline inflation should converge towards the Central Bank's inflation target by end-2018. Core inflation, which has been stubbornly high would also converge to the target. Using a variety of scenarios, we find that the downward trend looks relatively robust, save for potentially large upward pressure should there be important inflationary supply side shocks.

The remainder of the paper proceeds as follows. Section II sets out the background for studying Phillips curves in Colombia while Section III discusses the empirical methodology. Section IV presents the results. Last Section V presents various model evaluation exercises and then uses the Phillips curves as a forecasting tool. Section VI concludes.

\section{BACKGROUND AND RECENT DEVELOPMENTS}

Colombia adopted full-fledged inflation targeting in 1999, with inflation as the nominal anchor, a floating exchange rate, and the short-term interest rate as the main instrument. Since then Colombia has been able to achieve notably more stable inflation than in the past when it had a history of often high and volatile inflation. ${ }^{4}$ The central bank has been able to establish substantial credibility in a relatively brief period of time and has kept inflation close to the 3 percent target for extended periods of time.

Recently, the sharp depreciation of the peso in 2015-16, food price shocks in 2016, and the VAT increase in early 2017 were shocks with significant inflationary impacts. In February 2015 inflation moved above the 4 percent upper-tolerance limit. It has since come down from its peak of 9 percent in July 2016 and is now hovering around 4 percent. While

\footnotetext{
${ }^{4}$ The first calculations of CPI in Colombia were done by the Central Bank around 1923. In 1937 it started producing price indices from surveys of the working class of Bogota. This index measures the average cost of a goods and services basket representative of household final consumption, expressed in relation to a base period. The National Administrative Department of Statistics (DANE) took responsibility of the CPI in 1954 and regularly implements revisions to the index with the purpose of incorporating methodological and operative improvements to align the statistical production of the index with the new developments generated by more advanced statistical systems. In accordance with international standards, recommendations, and norms the last update to the CPI was in 2008. An update is due later this year in 2018.
} 
tradable and food inflation fell quickly back toward target once the supply shocks dissipated, core and non-tradable inflation remained significantly above 4 percent as of Q3 2017.

The diverging dynamics of individual inflation components warrant a closer look. One useful decomposition which the Central Bank provides, is a split of the CPI basket into four key subcomponents: tradable, non-tradable, regulated and food. Non-tradable make up the largest share of the CPI basket at over 30 percent, followed by food with 28 percent, tradables follow with 26 percent and lastly regulated prices with 15 percent. As Figure 1 shows, the four subcomponents of inflation have had very different dynamics over the past years. This suggests that they might be driven by different underlying processes. Tradable inflation is highly volatile, for example - even more so in the case of peer countries (Figure 2). On the other hand, non-tradable inflation is very stable and has been moving in the opposite direction of tradable inflation even when other countries in the region have a relationship that is moving closer together in the recent past.

Figure 1. Key Components of CPI Basket

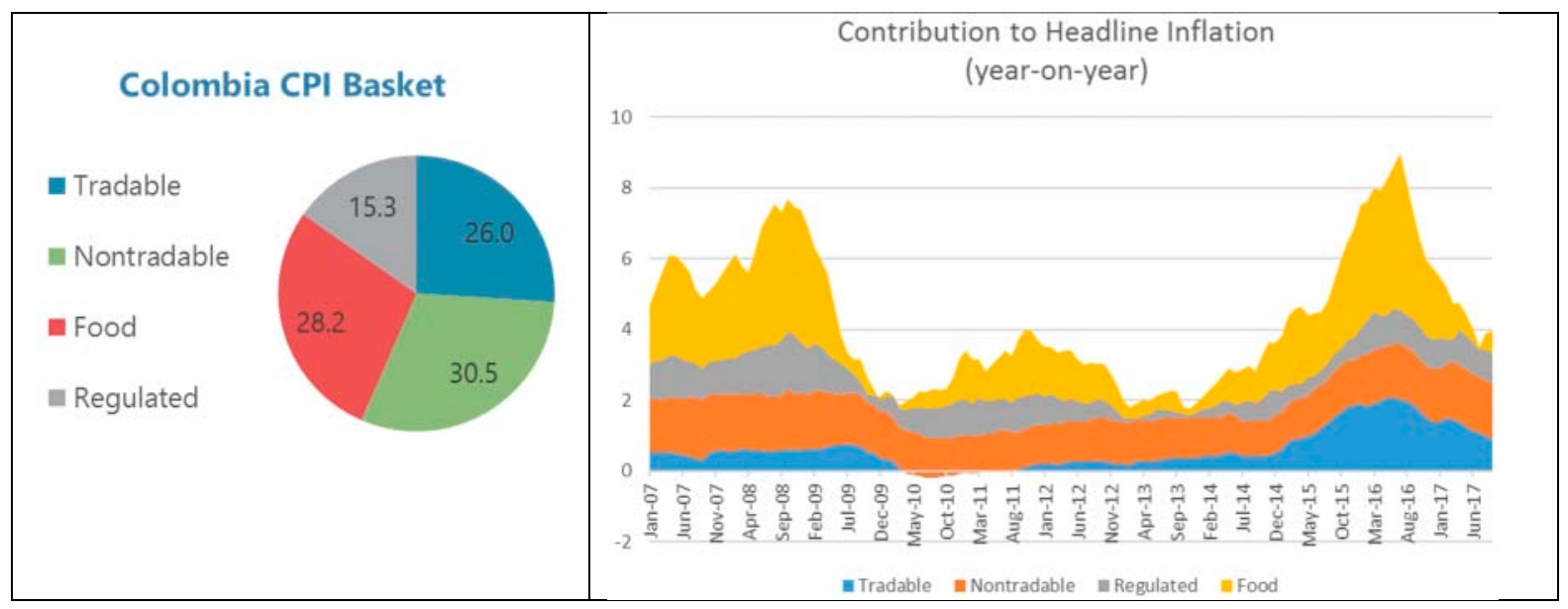

Figure 2. Volatility of Tradable and Non-tradable Inflation

(a) Standard deviation of monthly inflation in LA5

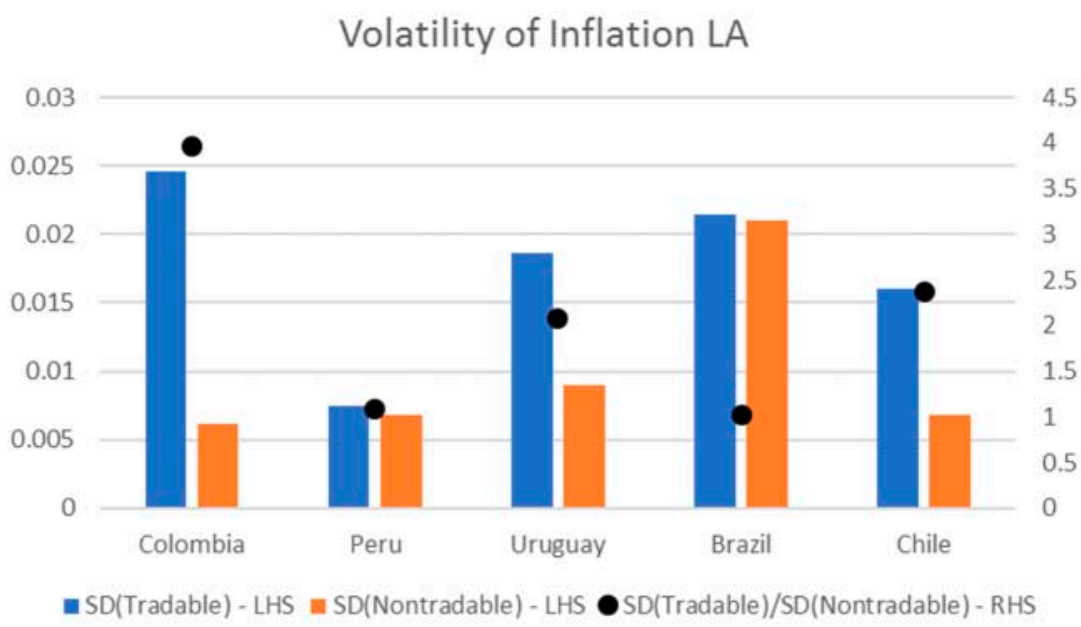




\section{(b) Tradable and non-tradable inflation in LA5}

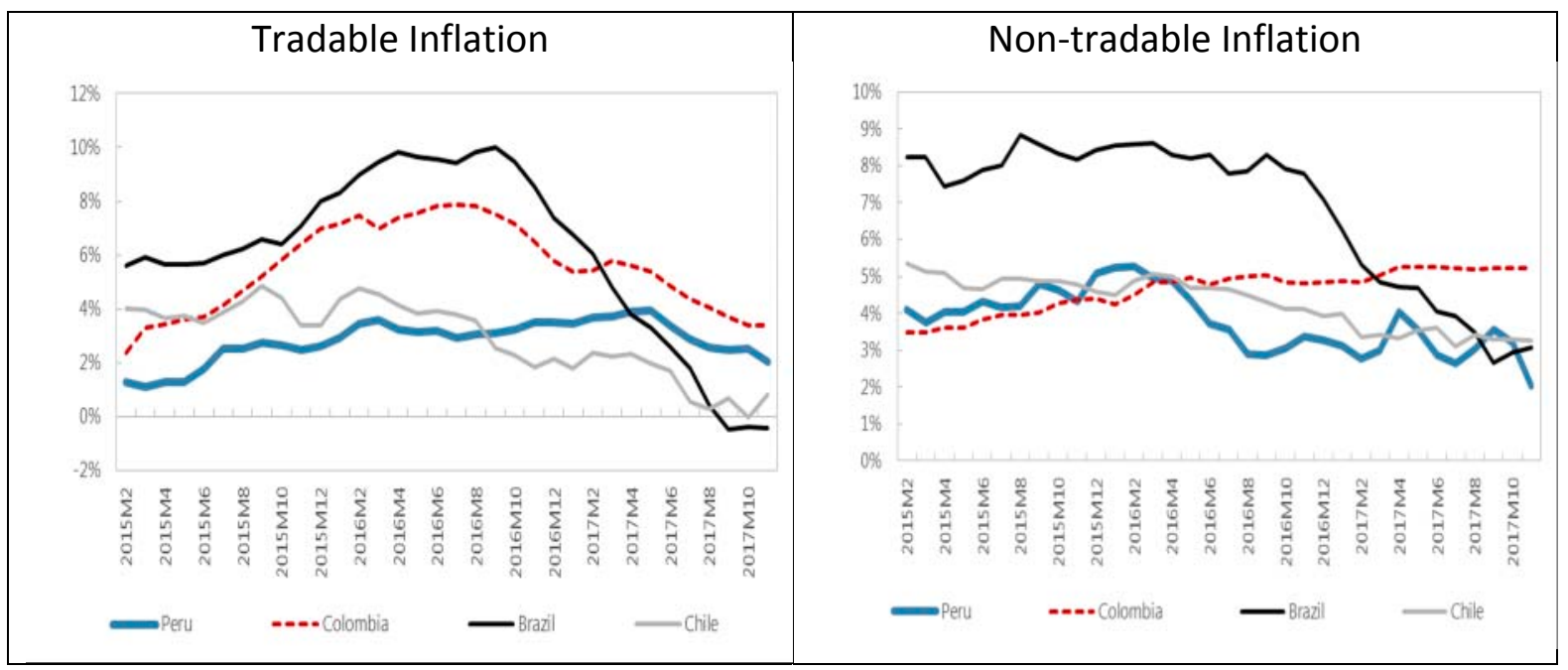

In this paper, we will aim to understand the drivers of each of the above mentioned four subcomponents of inflation in Colombia. ${ }^{5}$ To be able to capture the underlying dynamics as best possible we further decompose non-tradable inflation into rent (including imputed rent), education and 'other' where the latter captures the remaining components of the non-tradable basket. Indexation plays a key role for many components of non-tradable inflation - notably for both education and rent which depend in part on headline inflation at the end of the previous year. A finer decomposition is also helpful to allow us to study specific factors related to the rental and education markets. For example, rent might be impacted by housing market features such as mortgage interest rates. Education stands out as having had very high rates of inflation in the recent past, a phenomenon common to many countries in Latin America and perhaps driven by a lack of education supply in the face of rapidly growing middle classes.

Given that the indexation aspect of education and rental price setting makes them not fully marked determined, the 'other' component could be more closely thought of as the purely 'market-determined' component of non-tradable inflation. As can be seen in Figure 3 the 'other' component is somewhat more volatile than the other two, likely precisely because it is not indexed. ${ }^{6}$ At certain points in the paper we will work with a newly created index which we call 'purely market-determined core prices' which we define as the sum of tradable inflation and the 'other' component of non-tradable inflation. This index represents roughly one third of the overall CPI basket.

\footnotetext{
${ }^{5}$ For the remainder of the paper we define core inflation as the sum of tradable and non-tradable inflation (in other words, excluding regulated prices and food inflation).

${ }^{6}$ Around 50 percent of the 'other' component also contains some element of indexation. Only 10 percent of non-tradable goods are not indexed in any way.
} 
Figure 3. Components of Non-Tradable Inflation

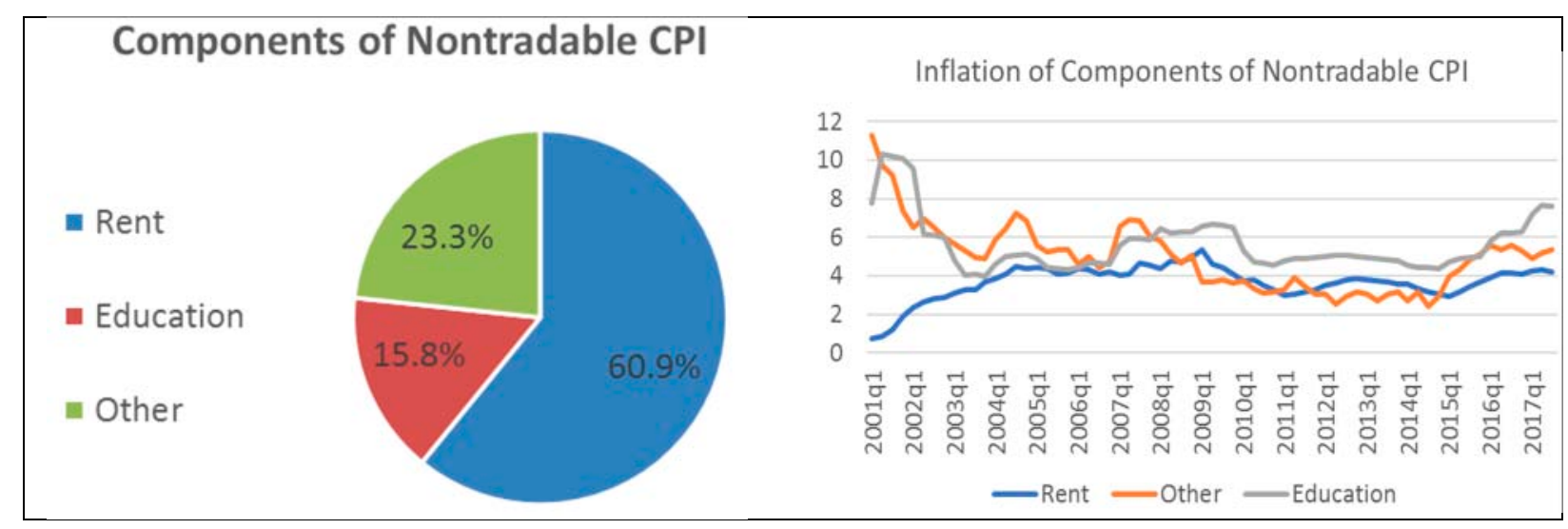

We model food inflation and tradable inflation without further decomposing the indices. ${ }^{7}$ However, we do decompose regulated prices. Figure 4 makes it clear that the subcomponents (fuel, public services and transportation) behave very differently and it is thus worth capturing the underlying drivers individually. Specifically, since the individual components are driven by formulas (as well as political decisions) we can try to capture elements of each formula when modelling inflation for each component.

Figure 4. Components of Regulated Prices

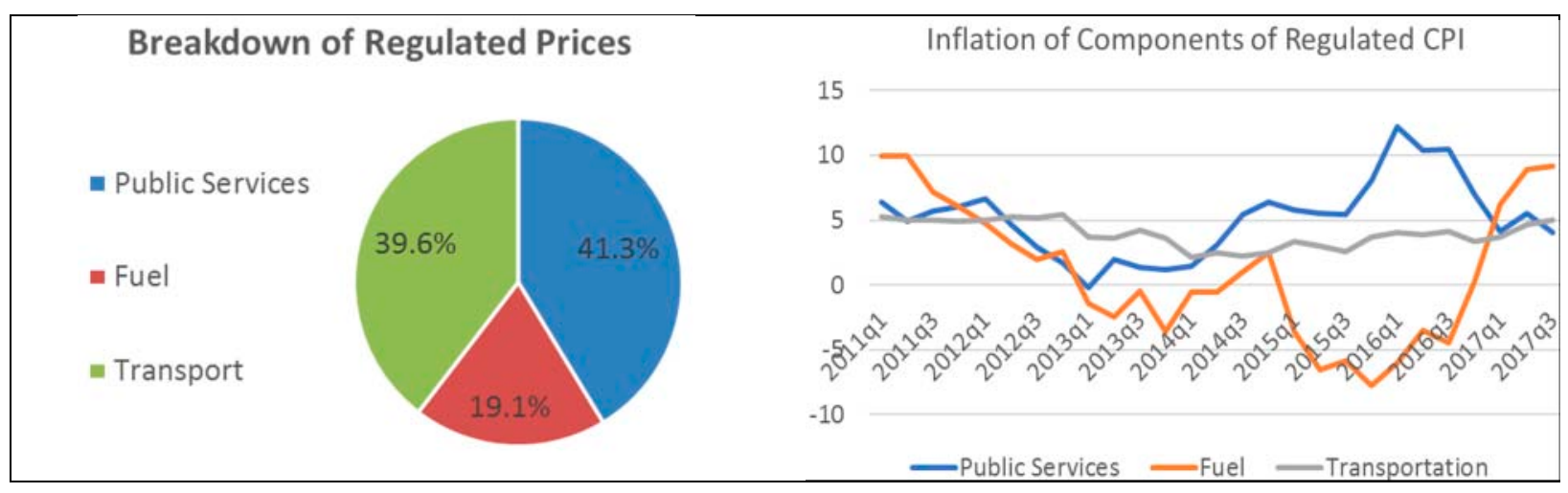

To gain a first impression of the Phillips curve relationship in Colombia we briefly inspect scatter plots between the output/unemployment gap and headline and core inflation, respectively, before we turn to a detailed look at the methodology we employ to model inflation in Section III.

Looking at Figure 5, which plots quarterly observations since 2001, suggests that from a naïve visual inspection, the Phillips curve relationship is Colombia is non-existent (or even has the wrong sign). The lack of any obvious bivariate relationship in the picture highlights the importance of controlling for other factors, notably the frequent and large supply shocks,

\footnotetext{
${ }^{7}$ Ideally it might be interesting to decompose tradable goods into durables and nondurables since they might be expected to behave differently.
} 
which pollute the relationship between prices and the business cycle in Colombia. Indeed, once we estimate the Phillips curve in an adequate framework as set out below, we find a significant relationship, with the expected sign.

Figure 5. Scatter Plots of Output and Unemployment Gap against Headline and Core Inflation
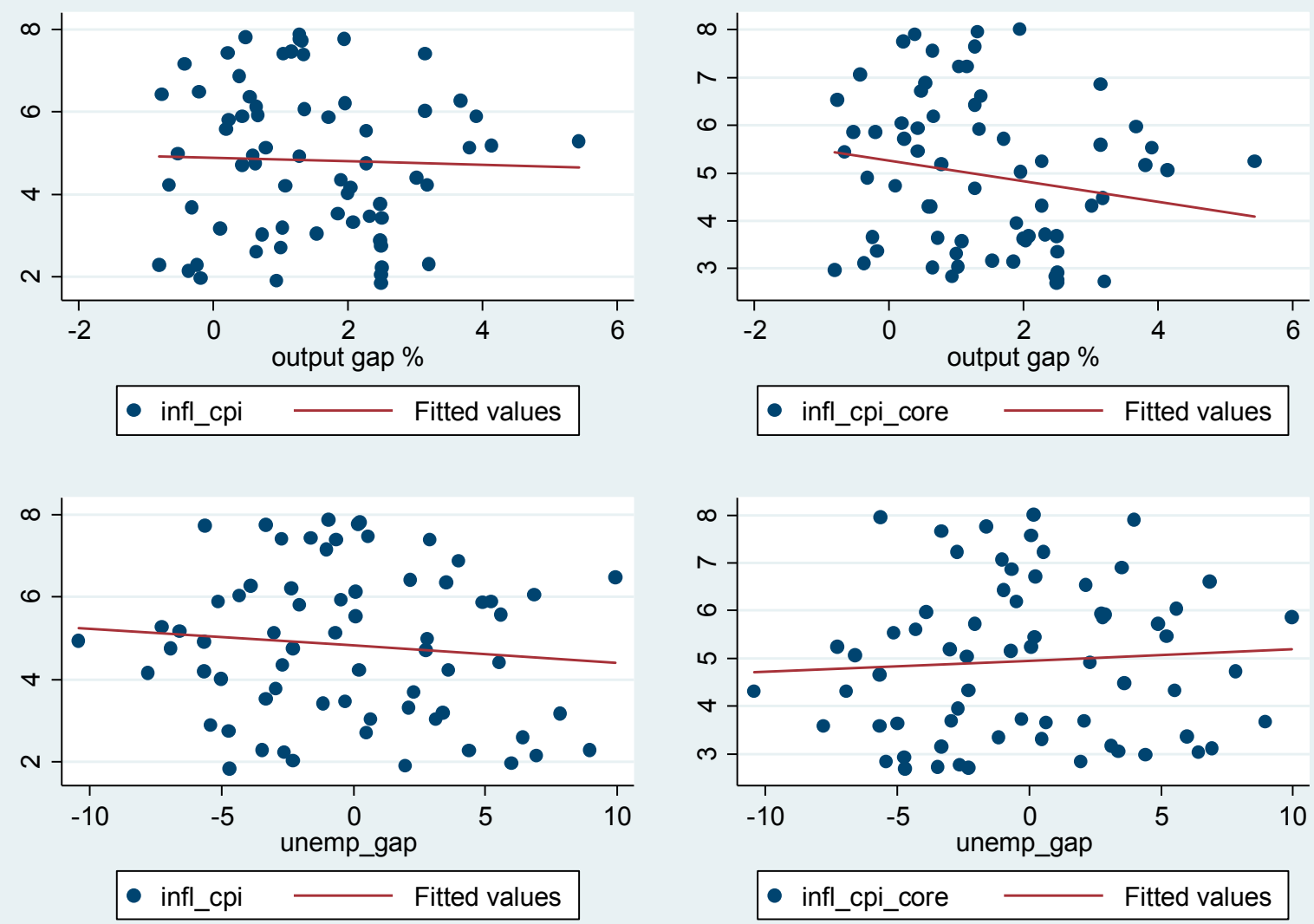

\section{Methodology}

\section{Conceptual Framework}

To explain inflation dynamics in Colombia we estimate a so-called triangle model of the Phillips curve (see Gordon 2011 for a summary) using quarterly data from Q1 2002 until Q3 2017.

$$
\pi_{t}=c+\alpha(L) \pi_{t-1}+\beta(L) g a p_{t}+\gamma(L) s_{t}+\theta \pi_{t+j}^{e}+\epsilon_{t}
$$

Equation (1) is an auto-regressive distributed lag model (ARDL). The model is 'triangular' because it captures the three drivers of inflation identified in mainstream economics (i) inertia; (ii) demand shocks proxied by the unemployment or output gap; and (iii) explicit 
supply-side shocks. In terms of notation, $\alpha, \beta$ and $\gamma$, are lag polynomials, $\pi_{t}$ is the $y / y$ inflation rate in period t, gap refers to either the output or unemployment gap ${ }^{8}, \pi_{t+j}^{e}$ are $\mathrm{j}$ periods ahead inflation expectations and $s$ is a vector of supply-side shocks. Lagged inflation captures inertia. The supply side is captured by variables which explicitly capture supply-side shocks such as movements in relative prices. It has been shown that omitting supply-side shocks can introduce large biases to Phillips curve estimates and given the frequent and large shocks experienced in Colombia, it is particularly important to adequately control for them. We include the forward-looking component of inflation by controlling for 24-month-ahead inflation expectations. ${ }^{9}$

Given that Colombia is a small-open economy, we are compelled to include open-economy Phillips curve components, namely international prices and the exchange rate. A direct way to capture the open-economy dynamics would be to include relative import prices (which can in turn be driven by NEER movements and world CPI) but since we do not have a basket of 'consumption import prices' in the case of Colombia we stick with NEER movements. We capture the international price component by including weighted trading partner CPI growth in the model.

The baseline set of supply-side factors in our specification also includes a VAT hike dummy and a dummy for extreme weather associated with the el Niño phenomenon. The latter is constructed based on the Southern Oscillation Index and takes the value one when the twoperiod sum of the index lies in the lower decile of the distribution (below -1.25). Last, we also include a variable which captures real wage shocks. Wage dynamics are relevant in the case of Colombia since centralized minimum wage setting means that wages are not necessarily only driven by market forces. ${ }^{10}$ In the baseline regressions we define this cost push factor variable as the residual of a regression of minimum wage increases on the output gap, labor productivity growth and past inflation - in other words the real minimum wage increases in excess of labor productivity growth and not explained by market pressures as proxied by the output gap. ${ }^{11}$

\footnotetext{
${ }^{8}$ We use the output gap in the baseline regressions and the unemployment gap in a robustness exercise. The reason is that the large informal sector might be diluting the role of the unemployment gap as a measure of economic slack.

${ }^{9}$ We avoid using 12-month-ahead expectations as they are highly correlated with current and lagged inflation.

${ }^{10}$ Note that in general wages are not included in the triangular model. Inflation-wage cycles are already captured through the inflation inertia terms and the output/unemployment gap represents the 'forcing' variable which translates market pressures into higher inflation. In particular, Gordon $(2011, \mathrm{p} 24)$ notes that as long as there is no wage-wage inertia (where wage increases are driven by past wage increases, irrespective of what happened to inflation), wages should not be included in a price Phillips curve. However, the fact that in Colombia minimum wage increases can be mandated independent of the business cycle and independent of productivity growth justifying the inclusion of a real wage shock variable.

${ }^{11}$ In robustness exercises we also use simpler measures such as just real minimum wage increases. Results are generally unchanged.
} 
Similar to Matheson (2006) and closely related to Abdih et. al (2016) we take a bottom-up approach to modelling inflation, by estimating individual Phillips curves for the key components of CPI inflation. As both papers show, this allows for a substantial improvement in terms of forecasting ability, but most importantly also sheds more light on the inflation process. $^{12}$

In the bottom-up Phillips curve estimations we keep the basic structure of equation (1) but add certain explanatory variables which are only relevant for specific components of the CPI basket. For example, when modelling rent inflation, we allow for the inclusion of mortgage interest rates as well as a lag of the price-rent ratio. Last, while the auto-regressive terms (the lag structure on past inflation) captures inertia for each sub-component, we also need to capture the explicit indexation arrangements which tie price changes in year $t$ for a certain item (education, rent) to headline inflation in year $\mathrm{t}-1$. To allow for this form of indexation, we include a variable which measures end of period headline inflation in the previous year in the equations for rent and education inflation.

Last, since regulated prices are not determined by market forces but either by an underlying formula or political decisions, we model them outside of our Phillips curve framework in a set of auxiliary regressions which take into account the idiosyncrasies of each component of regulated prices.

Summary Statistics

\begin{tabular}{lccc}
\hline Component & Observations & Mean & Standard Deviation \\
\hline Headline Inflation & 68 & 4.945 & 1.903 \\
Tradeable Inflation & 68 & 3.902 & 1.344 \\
Nontradeable Inflation & 68 & 3.361 & 2.675 \\
Regulated Inflation & 68 & 4.363 & 0.625 \\
Food Inflation & 68 & 6.118 & 3.430 \\
& & & \\
D.NEER & 75 & -0.204 & 3.850 \\
Output Gap & 76 & 0.002 & 1.278 \\
Unemployment Gap & 72 & 0.008 & 0.526 \\
2 year Inflation Expectations & 75 & 4.247 & 1.235 \\
\hline Trade Partner Weighted CPI & 72 & 2.672 & 0.923
\end{tabular}

\section{Estimation}

We adopt a systematic approach to choosing the appropriate specification for modeling inflation and its components. We select up to four lags of each variable on the basis of the Bayesian information criterion (BIC). We do not restrict lag length to be uniform across

\footnotetext{
${ }^{12}$ Given the reduced-form nature of the exercise a number of endogeneity concerns are unavoidable and have to be acknowledged. A more structural approach is able to overcome some of those concerns but generally at the cost of modelling inflation in a less disaggregated way.
} 
variables (eg, for a bivariate Phillips curve of headline inflation explained only by its own lags and the output gap we would estimate $4 * 5$ possible models and pick the one that minimizes the information criterion).

The magnitude of estimated ARDL coefficients does not always have a straightforward interpretation but can be used to retrieve short- and long-run impulse responses of inflation to changes in independent variables. Specifically, consider a bivariate version of the above $\operatorname{ARDL}(1, q)$ model.

$$
\pi_{t}=c+\alpha(L) \pi_{t-1}+\beta(Q) g a p_{t}+\epsilon_{t}
$$

which can also be written as

$$
\pi_{t}=c+\sum_{i=1}^{l} \alpha_{i} \pi_{t-i}+\sum_{j=0}^{q} \beta_{j} g a p_{t-j}+\epsilon_{t}
$$

Then the long-run impact of a change in gap on inflation (assuming stationarity) is given by $\frac{\sum_{j}^{q} \beta_{j}}{1-\sum_{i}^{l} \alpha_{i}}$ and the short-run impacts can be obtained as $\beta_{0}$ in the first period, $\beta_{1}+\beta_{0} \alpha_{1}$ in the second period, $\beta_{0} \alpha_{2}+\left(\beta_{1}+\beta_{0} \alpha_{1}\right) \alpha_{1}$ in the third period, and so on for additional horizons.

Note that the information criterion does not necessarily exclude variables which are not statistically significant (even though this is true most of the time). ${ }^{13}$ To gauge overall significance of individual included variables we report F-tests on the sum of the lag structure when we present the regression results in the following section.

\section{Understanding Inflation Using Phillips CuRVES}

\section{A. Top-Down Analysis of Headline and Core Inflation}

Before we turn to our bottom-up approach we present results for top-down headline inflation, core inflation and core market determined inflation regressions. Table 1 shows the variables and number of lags of each variable that minimize the information criterion in the regressions for headline inflation. The coefficients are intuitive - first, inertia is very high (as shown by the large and significant coefficients on the lagged dependent variable). Second, the impact of exchange rate movements is significant and has the expected sign (depreciations increase prices). Third, both higher world inflation and higher long-term inflation expectations in Colombia translate into higher inflation. Last, the Phillips curve coefficient (output gap) is positive as expected.

Table 2 repeats the exercise for core inflation, highlighting a few differences with headline inflation. Persistence remains high--a standard result in the literature (Gordon, 2011) but it is worth noting (and intuitive) that persistence is even higher for core than headline given the

\footnotetext{
${ }^{13}$ We do not let the information criterion choose lag length for the dependent variable. To control for base effects we always include four lags of the dependent variable.
} 
higher weight of non-tradables in core. The estimated impact of exchange rate movements is significantly higher in the case of headline, and as we will discuss below this is likely due to food prices (Colombia imports roughly 30 percent of its food consumption).

The coefficient on the output gap is positive both for headline and for core inflation but the point estimate is only significant in the case of core inflation, again a relatively intuitive result. We also estimated an equation for our index of core market determined inflation, for which we would expect market pressures to play the most direct role. And indeed, the estimated coefficient on the output gap is highly significant and larger than in the case of core inflation.

Table 1. Headline Inflation Specification

\begin{tabular}{lccc} 
Headline & Coefficient & SE & t-stat \\
\hline L1.Headline Inflation & 1.300 & 0.120 & 10.83 \\
L2. Headline Inflation & -0.683 & 0.195 & -3.5 \\
L3. Headline Inflation & 0.192 & 0.192 & 1 \\
L4. Headline Inflation & -0.023 & 0.118 & -0.2 \\
Output Gap & 0.098 & 0.062 & 1.59 \\
Nominal Effective Exchange Rate (Diff) & -0.020 & 0.011 & -1.77 \\
L1.Nominal Effective Exchange Rate (Diff) & -0.034 & 0.016 & -2.12 \\
L2.Nominal Effective Exchange Rate (Diff) & 0.046 & 0.016 & 2.88 \\
L3.Nominal Effective Exchange Rate (Diff) & -0.038 & 0.012 & -3.29 \\
Trade Partner Weighted CPI & 0.348 & 0.098 & 3.54 \\
2 Year Inflation Expectations & 0.174 & 0.109 & 1.6 \\
\hline & & & \\
Analysis of lag structure, coefficients: & Sum(Coeff.) & Joint F-Stat & Joint Prob F \\
\hline Headline Inflation & 0.785 & 202.38 & $0.00 * * *$ \\
Output Gap & 0.098 & 2.53 & 0.1182 \\
Nominal Effective Exchange Rate (Diff) & -0.046 & 17.2 & $0.0001 * * *$ \\
Trade Partner Weighted CPI & 0.348 & 12.55 & $0.0009^{* * *}$ \\
2 Year Inflation Expectations & 0.174 & 2.55 & 0.1165 \\
\hline
\end{tabular}

To be able to gauge the magnitude of the estimated coefficients better, and in particular to understand the slope of the Phillips curve, we constructed impulse response functions and calculated the long-term impact for a one percent increase in the output gap as described in Section III. We can distinguish three measures of the Phillips curve relationship which might be of interest: (i) the impact effect which is given by the point estimate on the contemporaneous output gap measure, (ii) the short-to-medium-run impact over a number of quarters and (iii) the long-run impact after all the dynamics of the model have played out. For (i) we get coefficients of $0.098,0.044$ and 0.096 in the case of headline, core and core market-determined, respectively. These estimates by themselves suggest a very flat Phillips curve. Figure 6 shows impulse response functions (IRFs) to see what the slope of the Phillips 
curve is over several quarters and Table 3 gives the long-run impact. After 6 quarters, we get an estimated Phillips curve coefficient that ranges between 0.29 and 0.53 and the final longrun coefficients lie between 0.55 and essentially unity, the latter for the core marketdetermined index. The results make it clear that it takes a while for demand pressures to work their way into higher prices.

Julio et al. (2017) also find a relatively flat Phillips curve during our sample period which they explain by a very flat curve for rigid prices (closely related to non-tradables). We will turn to our bottom-up analysis in the next subsection.

Table 2. Core Inflation Specification

\begin{tabular}{lrccc} 
Core & Coefficient & SE & t-stat & t-prob \\
\hline L1.Core Inflation & 1.358 & 0.123 & 11.03 & $0^{* * *}$ \\
L2.Core Inflation & -0.719 & 0.199 & -3.62 & $0.001^{* * *}$ \\
L3.Core Inflation & 0.338 & 0.195 & 1.73 & $0.09^{*}$ \\
L4.Core Inflation & -0.083 & 0.106 & -0.78 & 0.438 \\
Output Gap & 0.044 & 0.026 & 1.68 & $0.099^{*}$ \\
Nominal Effective Exchange Rate (Diff) & -0.019 & 0.004 & -5.19 & $0^{* * *}$ \\
Trade Partner Weighted CPI & 0.052 & 0.035 & 1.47 & 0.148 \\
El Niño & 0.155 & 0.091 & 1.7 & $0.094^{*}$ \\
VAT & 0.858 & 0.236 & 3.63 & $0.001^{* * *}$ \\
2 Year Inflation Expectations & 0.049 & 0.048 & 1.02 & 0.314 \\
\hline
\end{tabular}

Analysis of lag structure, coefficients: Sum(Coeff.) Joint F-Stat Joint Prob F

\begin{tabular}{lccc} 
Core Inflation & 0.893 & 904.38 & $0^{* * *}$ \\
Output Gap & 0.044 & 2.82 & $0.0989^{*}$ \\
Nominal Effective Exchange Rate (Diff) & -0.019 & 26.95 & $0^{* * *}$ \\
Trade Partner Weighted CPI & 0.052 & 2.16 & 0.1478 \\
El Niño & 0.155 & 2.9 & $0.0943^{*}$ \\
VAT & 0.858 & 13.18 & $0.0006^{* * *}$ \\
2 Year Inflation Expectations & 0.049 & 1.03 & 0.3138 \\
\hline
\end{tabular}

As a first robustness check, Table 3 shows the estimated coefficients when using the unemployment rather than the output gap. ${ }^{14}$ Note that the sign flips since a higher unemployment gap, implies a lower (or more negative) output gap. Looking at the impact of a one standard deviation shock shows that the results are very similar when using the unemployment gap instead of the output gap. As a separate robustness check we also re-

\footnotetext{
14 The unemployment gap is constructed using a simple Hodrick-Prescott filter for the quarterly data.
} 
estimate the regressions using quarter on quarter rather than year on year growth rates. ${ }^{15}$ Using quarterly growth rates is preferable from a conceptual point of view since it allows for a cleaner structural interpretation of the Phillips curve coefficient. ${ }^{16}$ Table $3 \mathrm{c}$ shows that the long-run coefficients using the quarter-on-quarter growth rates are broadly comparable to the year-on-year estimates as are the impact coefficients (except for headline inflation, due to a very large estimated impact on food inflation when using quarter-on-quarter rates). ${ }^{17}$

Figure 6. Reaction of Inflation to one Percentage Point Increase in Output Gap

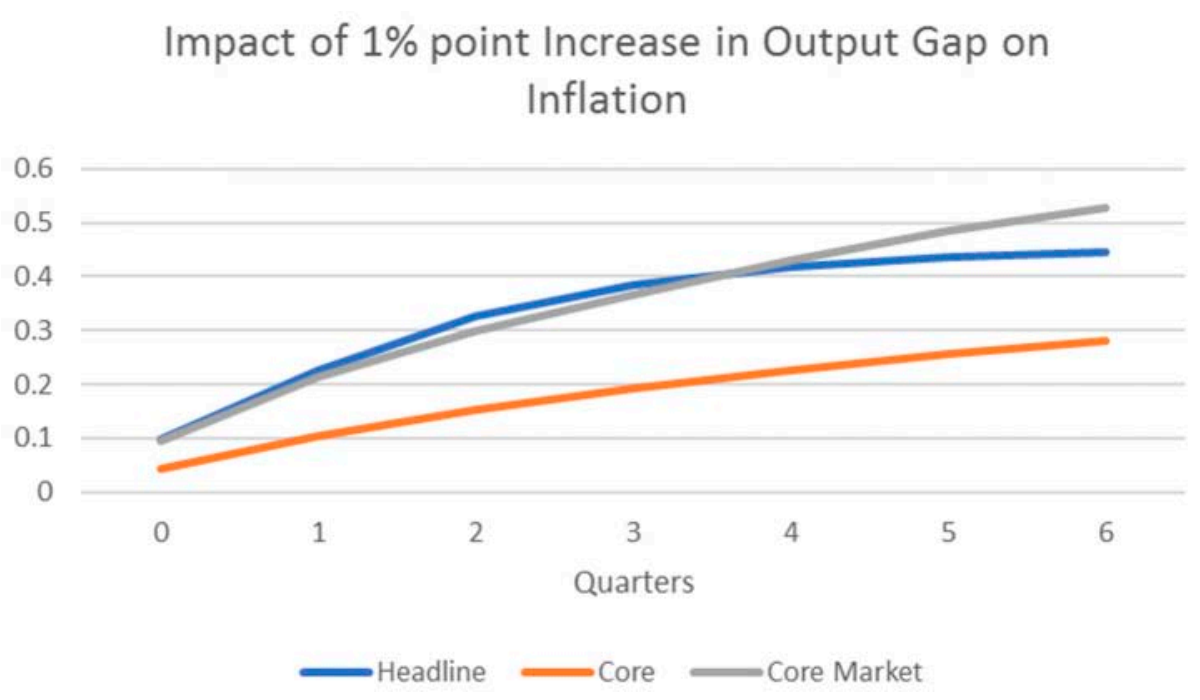

\footnotetext{
${ }^{15}$ We seasonally adjusted the inflation series using the census bureau X-12 method so calculate seasonally adjusted, annualized quarterly inflation rates.

${ }^{16} \mathrm{We}$ do not use quarter-on-quarter growth rates as the baseline because the high quarterly volatility due to idiosyncratic factors makes forecasting less reliable.

${ }^{17}$ Possible non-linearities in the Phillips curve could usefully be explored even though the (naturally) limited data availability for extreme scenarios makes this a challenging exercise.
} 
Table 3. Phillips Curve in Colombia

(a) Long-run Impact of 1 standard deviation increase

\begin{tabular}{l|rr} 
& & \\
& Output Gap & Unemployment Gap \\
\hline Headline & 0.58 & -0.31 \\
Core & 0.55 & -0.63 \\
Core Market & 0.95 & -1.00
\end{tabular}

(b) Long-run Impact of 1 percentage point increase

\begin{tabular}{l|rr} 
& & \\
& Output Gap & Unemployment Gap \\
\hline Headline & 0.46 & -0.60 \\
Core & 0.41 & -1.20 \\
Core Market & 0.74 & -1.90
\end{tabular}

(c) Impact of 1 percentage point increase (q-o-q seasonally adjusted growth rates)

\begin{tabular}{l|cc} 
& Impact & \multicolumn{2}{|c}{ Long-Run } \\
\hline Headline & 0.51 & 0.82 \\
Core & 0.14 & 0.46 \\
Core Market & 0.11 & 0.54
\end{tabular}

One consistent result worth highlighting early on, is that our measure of wage cost push is never included in the final specification by the information criterion (with the exception of the regression for rent inflation). ${ }^{18}$ This suggests that conditional on adequately controlling for inertia (such as price-wage spirals) through a dependent variable lag structure, as well as controlling for demand and supply side pressures, minimum wage increases do not have much explanatory power in the regressions. Figure 7 illustrates why this might be the case. While the level of minimum wages in Colombia is high (relative to median income for example - see OECD (2016)), minimum wage growth has tended to follow inflation in the previous year quite closely and real wage increases controlling for productivity have been moderate in most, but not all, years between 2000 and 2017.

\footnotetext{
${ }^{18}$ We tried a number of alternative specification for the minimum wage such as a simple measure of real minimum wage increases but the variable always gets either dropped by the information criterion or on the few occasions where it is included it is insignificant [according to the F test?].
} 


\section{Figure 7. Real Minimum Wage Increases}

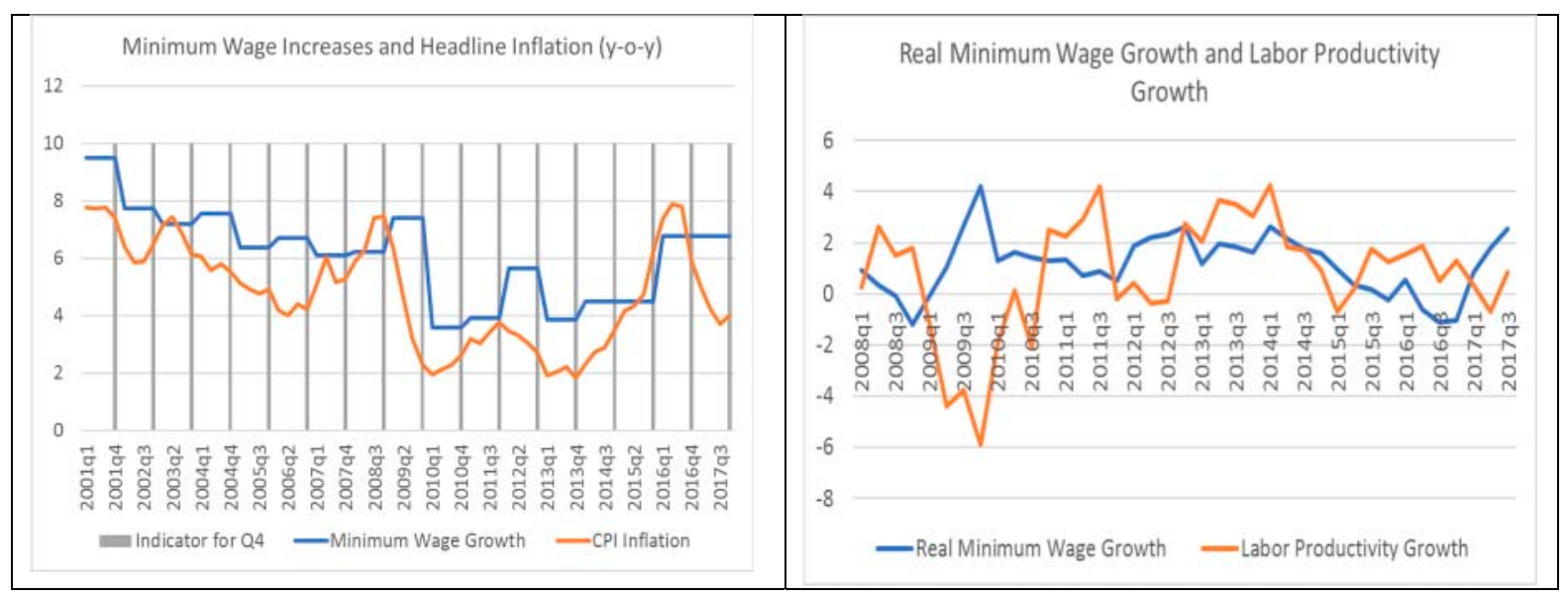

\section{B. A Bottom-Up Approach}

In this section, we model tradable, non-tradable, food, and regulated price inflation separately to understand the drivers of inflation dynamics in more detail. Regression tables are relegated to the Appendix in the interest of space. We find an important role for supply-side shocks in the bottom-up Phillips curves. Weather shocks, exchange rate movements, international price movements, and the VAT hike all have important impacts on inflation, particularly on tradable and food inflation. Rent and education inflation are strongly influenced by inertia and indexation. Regulated prices behave according to their own processes, with fuel broadly tracking Gulf of Mexico gasoline prices, for example.

\section{Tradable}

In line with Julio et al. (2017), we find a strong impact of exchange rate movements on tradable prices (significant at the 1 percent level) as well as a relatively strong impact of the output gap. ${ }^{19}$ Inflation expectations also have a large positive impact on tradable inflation (Figure 8). Further, the El Niño indicator and the VAT dummy were also selected by the information criteria for inclusion in the model and have the expected sign.

\section{Non-tradable}

We split non-tradable inflation into rent, education and 'other' as mentioned previously. In the rent equation, we allow additional factors to enter - notably an index for new home prices, real mortgage interest rates, and the lagged price-to-rent ratio. Only the index for new home prices is selected in the final specification. To capture indexation, we also include end of period headline inflation of the previous year in the estimation. The results show that

\footnotetext{
${ }^{19}$ Figure 7 shows exchange rate pass-through for tradable prices. Our estimated pass-through to headline inflation is driven by this tradable effect as well as the impact of exchange rate movements on food prices and is somewhat higher than those estimated in an IMF Colombia 2016 Article IV Special Issues Paper and IMF Western Hemisphere Department Regional Economic Outlook
} 
persistence and indexation dominate the dynamics of rent inflation. World inflation enters with a statistically significant positive coefficient but it is not clear whether this might be spurious given that no clear channel for such effect exists.

Figure 8. Reaction of Tradable Inflation to one Percentage Point Increase in Key Determinants

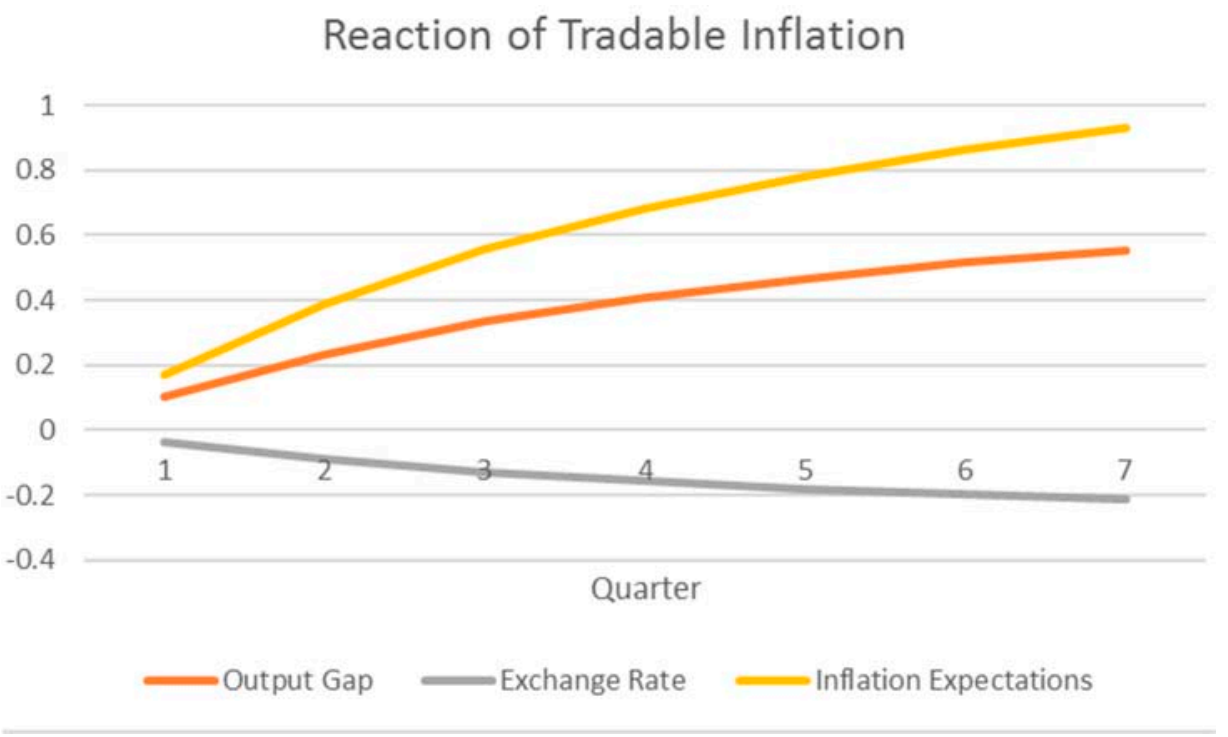

Similarly, for education, indexation is a key driver. A number of the other coefficients appear spurious, suggesting that education dynamics are not fully adequately modelled. ${ }^{20}$ Ideally, we would like to include variables which specifically capture supply and demand in the education market but we were not able to identify relevant available data. Studying education inflation in more detail in the future would be an interesting exercise given its elevated level and the consistent pattern of education inflation exceeding headline inflation in much of Latin America (see Figure 9).

Last, for the 'other' component of non-tradables, we again find very high but none of the other included variables (output gap, exchange rate and indexation) are statistically significant.

\footnotetext{
${ }^{20}$ Public education is free in Colombia. For private education up until high school, the Ministry of Education fixes maximum increases for the following year by decree around September. The increases are meant to be based on headline CPI inflation but since end of year CPI inflation is not known at the time of the decree, the Ministry can use either forecasts or latest actual data. On top of the basic maximum increase (4 percent for 2018) the Ministry sets incentives for good performing schools by allowing them additional increases. Counting all incentives and base increases the average increase for 2018 as set out in the September 2017 decree will be 5.9 percent, less than the previous year. For higher education, an index of costs which broadly follows CPI inflation is calculated as a suggestion for price increases but the universities are free to deviate from the index when setting their price increases.
} 
Since rent and education prices do not seem to be positively impacted by aggregate demand pressures in a significant way, the disaggregated results explain why we found a steeper Phillips curve for core market prices than for core prices.

\section{Food}

Food inflation dynamics are dominated by supply shocks related to international prices, the weather, and the exchange rate. Additionally, we estimate a large and significant coefficient for the output gap. In Section V, where we discuss forecasting, we will see in more detail the key role that supply-side shocks have for food prices.

\section{Figure 9. Inflation of Education Costs in Latin America}

\section{Difference between Education Inflation and} Headline Inflation

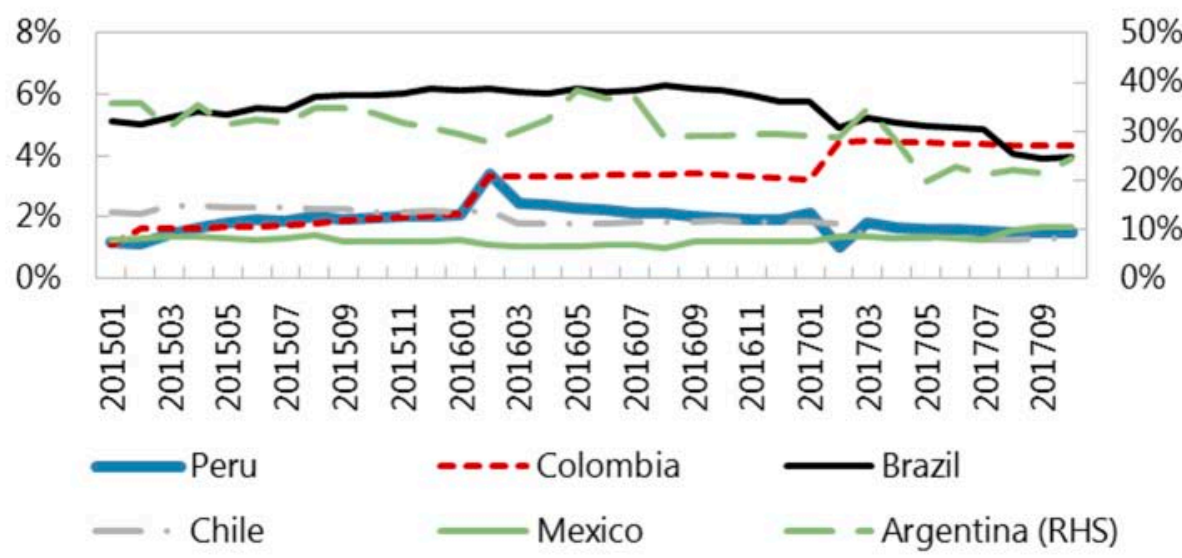

\section{Regulated Prices}

We disaggregate regulated prices into public services, fuel, and transportation price indices. We use auxiliary regressions instead of the baseline approach to give these subcomponents their own specification reflecting the particularities of their pricing formulas. Specifically, we model fuel price inflation as a function of lags of the growth rate of Gulf of Mexico gasoline prices given that the formula to determine fuel prices takes these into account. We also include the VAT shock and headline inflation in the previous year. To explain public services inflation, we include the indexation variable as well as the el Nino dummy (given that the composition of electricity supply can change with extreme weather events, for example). Last, for transportation we only include the indexation variable (i.e. headline inflation at the end of the previous year). The specifications for regulated prices generally fit the data reasonably well and substantially improve on the forecasting performance of a simple autoregressive process - and thus improve our headline inflation forecasts as we will see in the next section. 


\section{Forecasting Inflation Using Phillips Curves}

\section{A. Model Evaluation: Pseudo Out-of-Sample Forecasts}

To evaluate how well our models perform in forecasting inflation for Colombia, we reestimate the final specifications chosen for each inflation subcomponent three times and restrict the sample period to end in 2016 Q2, 2016 Q3 or 2016 Q4, respectively. We then forecast each inflation index "pseudo out-of-sample" over 2016 Q3/2016 Q4/2017 Q1—2017 Q3 and compare it to the actual inflation data. To summarize the goodness of fit we calculate the root mean square error (RMSE) and compare it to the RMSE of a simple autoregressive process - AR(4) - which provides a benchmark. ${ }^{21}$ For headline inflation we calculate two forecasts - one top-down taken directly from the CPI inflation regressions, and one bottomup where we sum up the forecasts for tradable, the components of non-tradable, the components of regulated and food. We also compare the top-down with the bottom-up forecast performance.

Both the top-down and bottom-up forecasts substantially improve on a simple AR process. Furthermore, the bottom-up approach improves on the top-down one. The forecasts here are dynamic, i.e. they use projected values of the dependent variable after $t+1$ rather than actual values and thus give a meaningful evaluation of the forecasting performance of the models. Figure 10 shows the RMSE of the top-down, bottom-up and simple AR process for headline and core inflation averaged over the three pseudo out of sample exercises.

\section{Figure 10. Pseudo-out-of-Sample Forecast Performance}

a) Summary of RMSE by Model

\section{RMSE - Pseudo Out-of-Sample Forecasts}

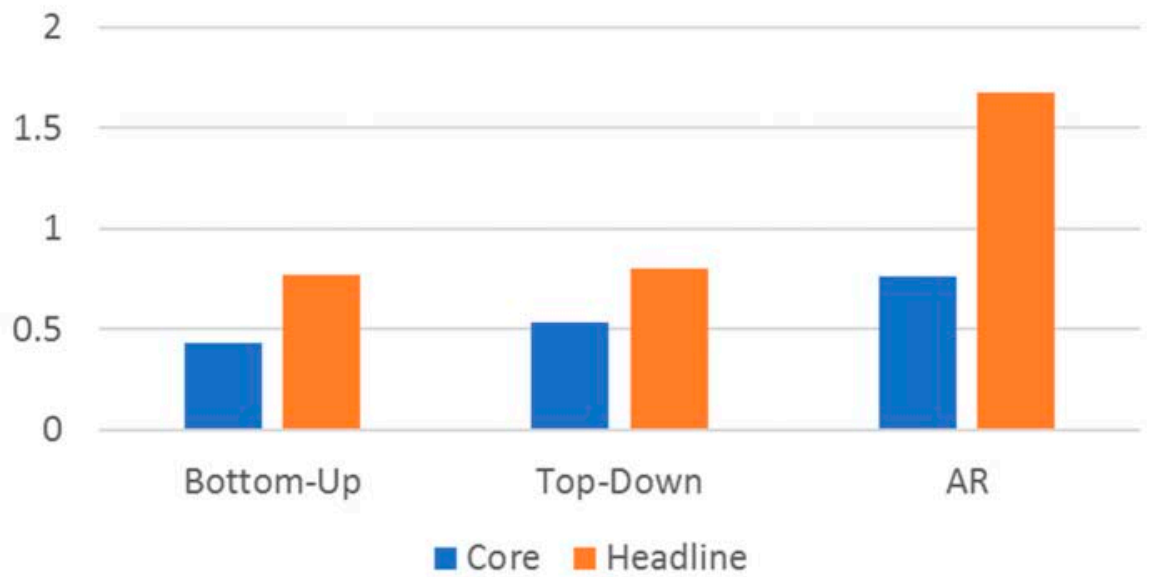

\footnotetext{
${ }^{21}$ One thing to keep in mind is that we chose our models to minimize information criteria (specifically the BIC) The BIC offers an estimate of the relative information lost when a given model is used to represent the process that generated the data and chooses the model which loses the least information. This is not necessarily equivalent to choosing a model which provides the smallest pseudo out of sample root mean square error.
} 
b) Headline Pseudo Out-of-Sample Forecast using bottom-up and pure AR

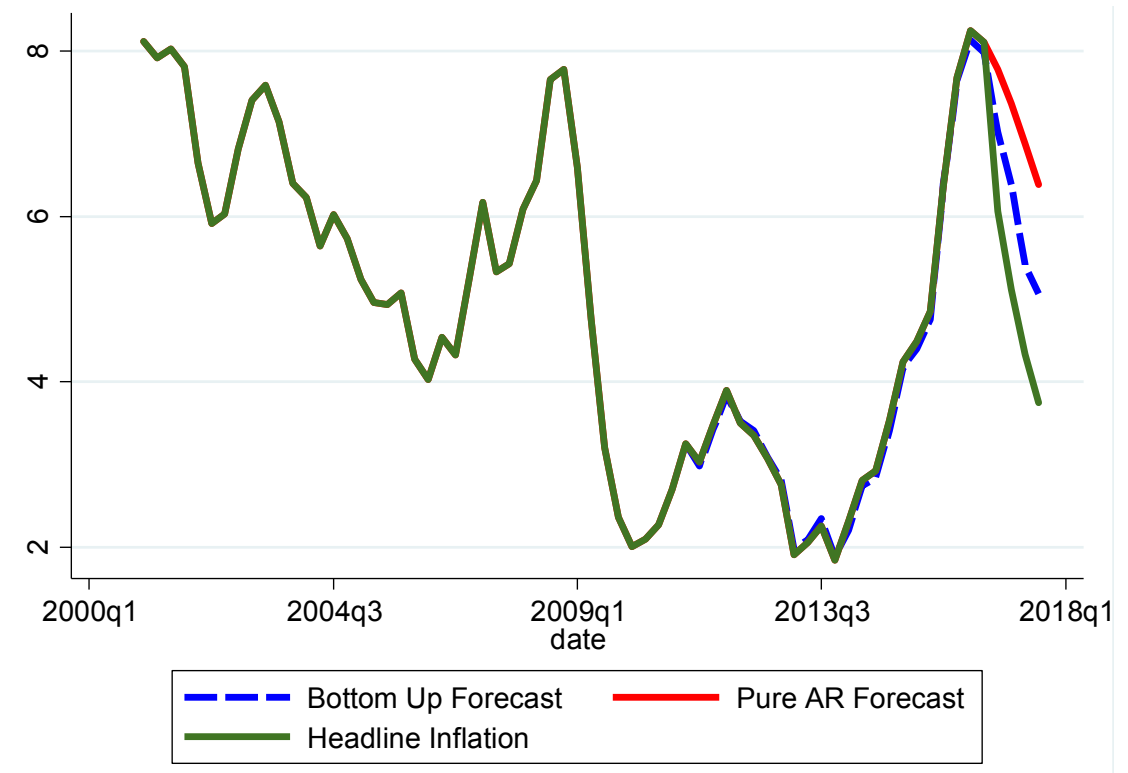

Figure 11 plots the RMSE of each pseudo out of sample forecast by component (left-hand chart). Two components stand out in terms of the absolute value of the RMSE-food and fuel. Nevertheless, as the right-hand side of Figure 11 shows, the RMSE of our specifications for these components is significantly lower than that of the pure AR processes.

Figure 11. Pseudo-out-of-Sample Forecast Performance by Component

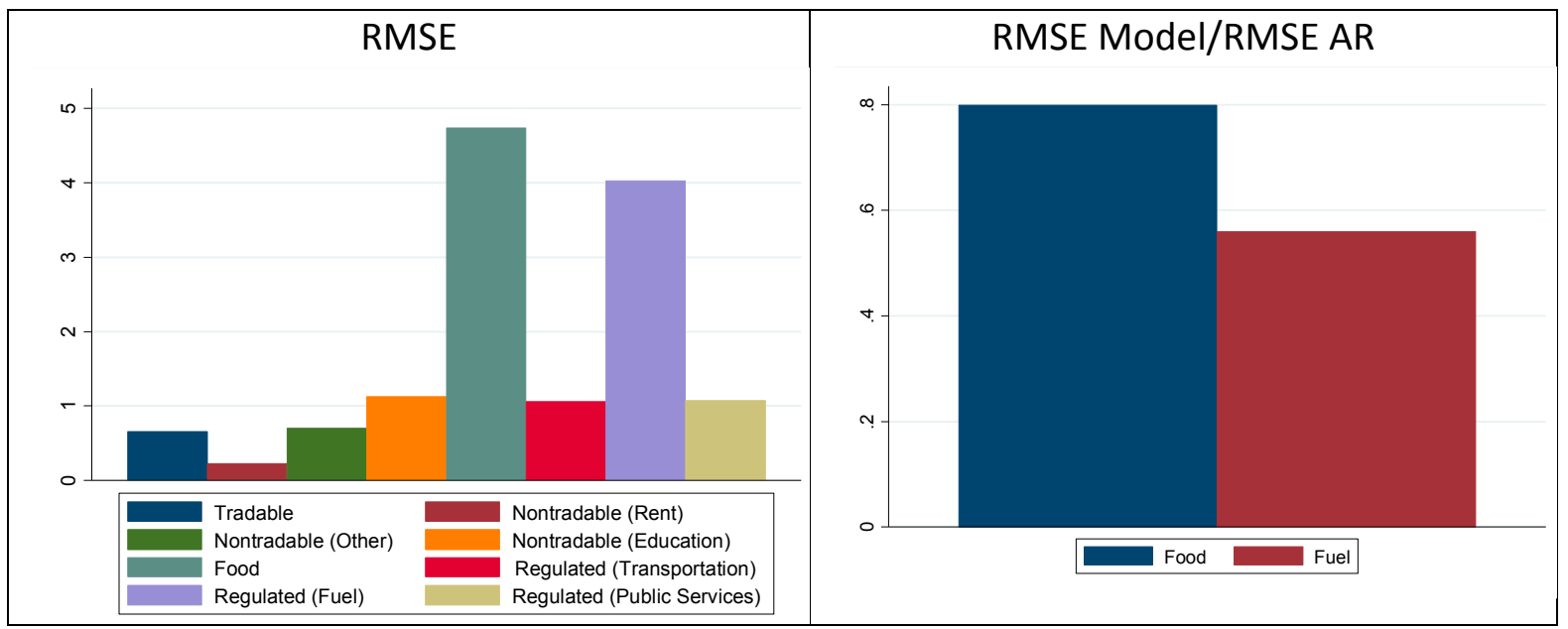

Figure 12 looks at the two components which stood out in Figure 10 in more detail..$^{22}$ The picture is reassuring - the regressions capture the movements in fuel and food inflation relatively well. The RMSE is higher for these components than for others simply because of the higher volatility of especially the food and fuel series.

${ }^{22}$ We use the one-year pseudo out of sample forecast for these graphs (Q4 2016 - Q3 2017). 
Overall, the models do well at modelling headline inflation as well as modelling the subcomponents. Most importantly, the models improve meaningfully on naïve AR forecasts and the bottom-up forecast improves on the top-down forecast.

Figure 12. Pseudo-out-of-Sample Forecast Performance for Food and Fuel

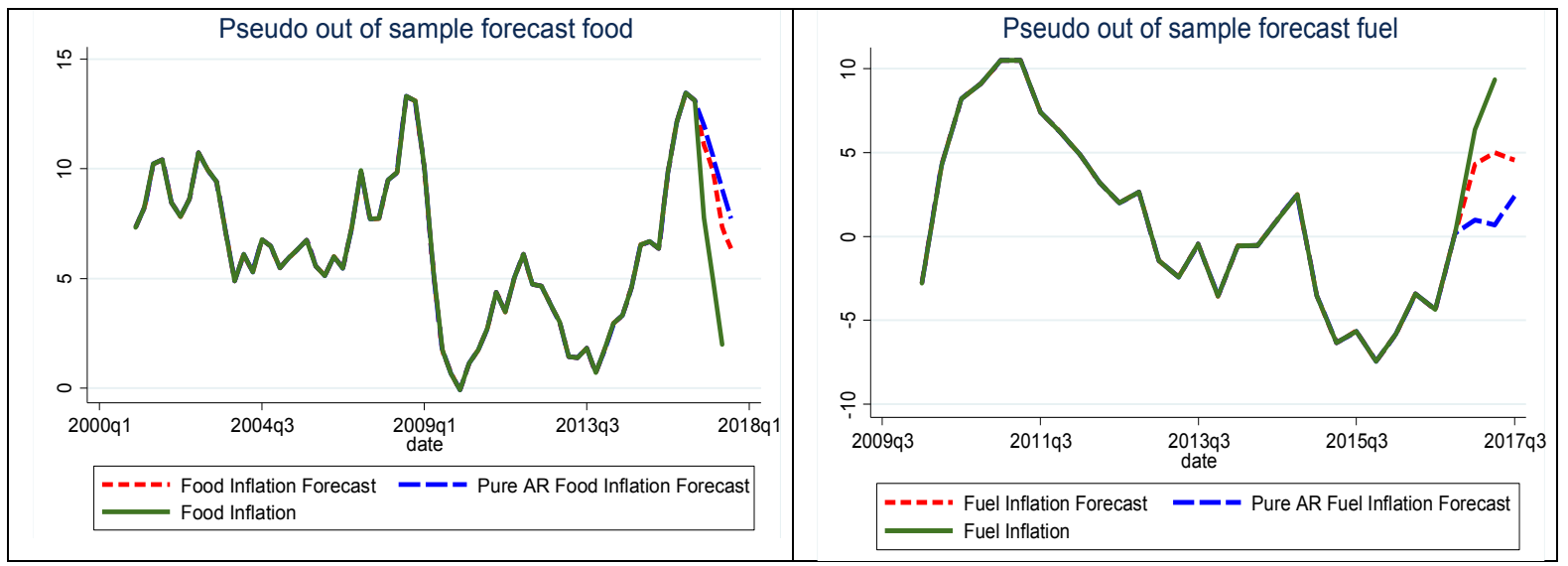

\section{B. Model Evaluation: Residuals}

We use the Breusch-Godfrey LM test to confirm that there is no residual auto-correlation in the residuals of the estimated models. We also use Engle's LM test to check whether there is autoregressive conditional heteroscedasticity $(\mathrm{ARCH})$ in the residuals. We can never reject the $\mathrm{H} 0$ of no auto-correlation and no ARCH-effects, respectively.

\section{Inflation Forecasts}

\section{Baseline Forecast}

We use the estimated models to forecast inflation over 2018 Q1 to 2018 Q4. We use the January 2018 IMF WEO values for our explanatory variables. We assume no supply side shocks other than exchange rate movements as taken from WEO forecasts and we assume that long-term inflation expectations are constant at 3.3 percent.

Figure 13 shows the baseline top-down and bottom-up forecast for headline inflation. The two forecasts are close and project inflation to converge towards the target level of 3 percent, reaching about 3.3 percent in Q4 2018 in the case of the bottom-up approach which project somewhat lower inflation than the top-down one.

Non-tradable inflation is forecast to come down slowly, falling below 4 percent only at the very end of the forecast horizon, while tradable inflation should be close to the 3 percent target for the whole year in the baseline scenario. 
Figure 13. Baseline Inflation Forecast for 2018

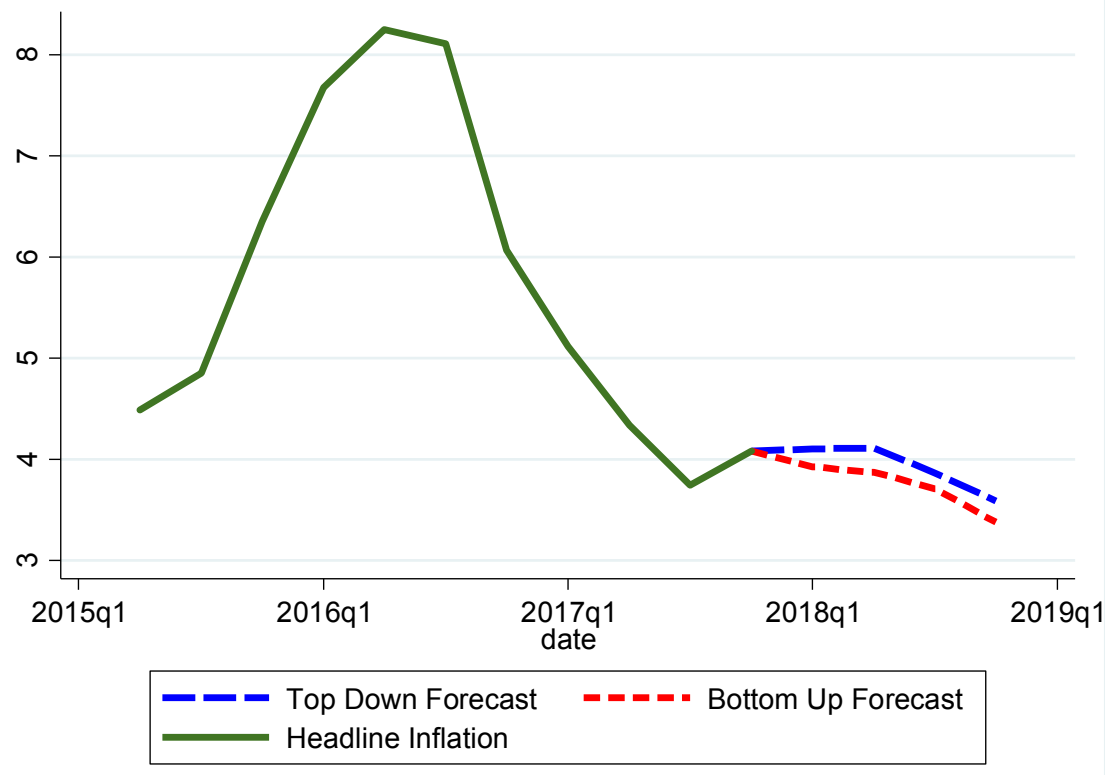

Figure 14. Tradable and Non-tradable Inflation Forecast for 2018

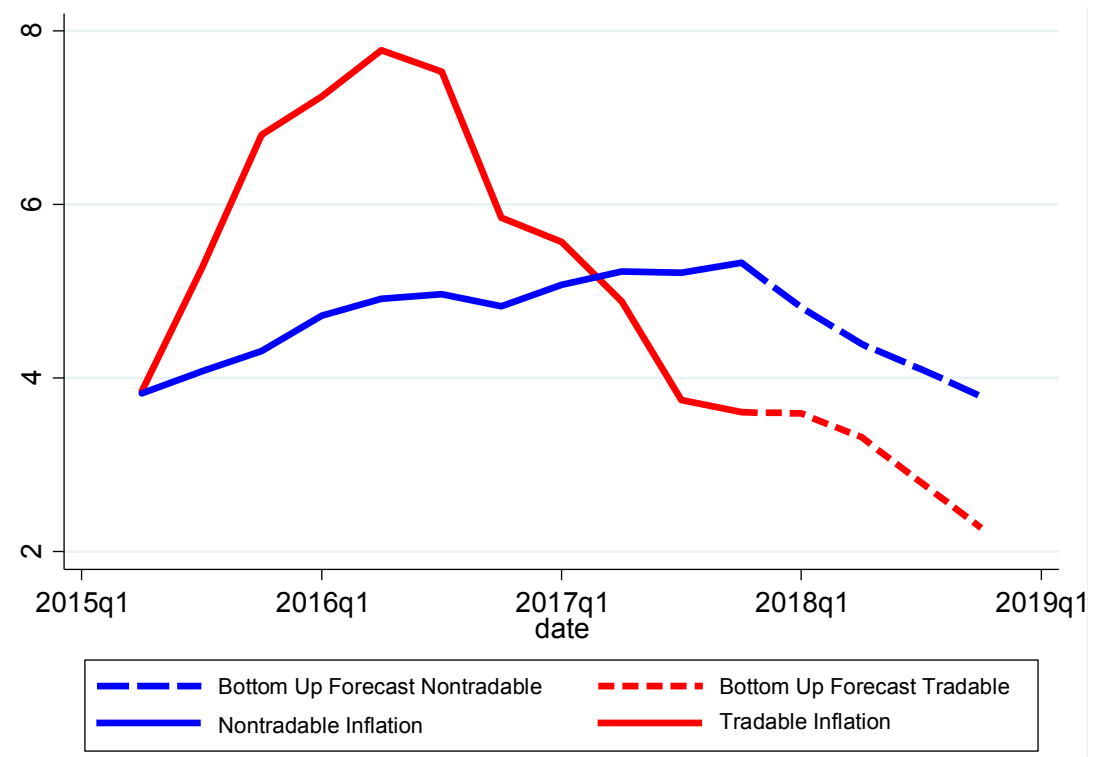

\section{Forecast Scenarios}

To understand the impact of specific factors better and test the sensitivity of the baseline forecast to the materialization of shocks or alternative economic developments we study various potential scenarios.

We present four scenarios: (i) 10 percent exchange rate appreciation in Q1 2018 with the exchange rate path for the remainder of the year as in the WEO baseline; (ii) a weather shock (E1 Nino) in Q1 and Q2 of 2018; (iii) lower GDP growth than in baseline such that the output 
gap at end-2018 is 1 percentage point lower than under the baseline; and (iv) an extreme adverse scenario with a 20 percent depreciation and a persistent el Nino shock. All forecasts in this section are constructed bottom-up to exploit the full information contained in the regressions.

Figure 15a and $\mathrm{b}$ show the impact of the different scenarios on headline and core inflation. Several things stand out. First, a 10 percent appreciation shock (over and above the WEO baseline) would push inflation to or even below the inflation target. A short weather shock would mainly affect headline inflation and would take it away from the target. However, the impact would moderate relatively quickly.

A worsening in the output gap of 1 percent of GDP by end-2018 would only have a modest impact on both headline and core inflation. As we observed previously, the short-run slope of the Phillips curve is relatively flat so that a 1 percentage point increase in the output gap only translates into a decrease in inflation of roughly 0.2 percent over the forecast horizon.

Last, the adverse scenario which combines two important supply shocks, has large impacts on inflation. Under this scenario headline and core inflation would both rise throughout the year and finish 2018 at close to 7 and 5.5 percent, respectively. The impact would operate via much higher food and tradable inflation, while non-tradables would hardly be affected during the forecast horizon (but would rise in 2019 due to indexation). Clearly the adverse scenario is quite extreme but it does highlight how susceptible inflation developments are to large supply shocks.

\section{Figure 15. Forecast Scenarios}

\section{a) Headline Inflation}

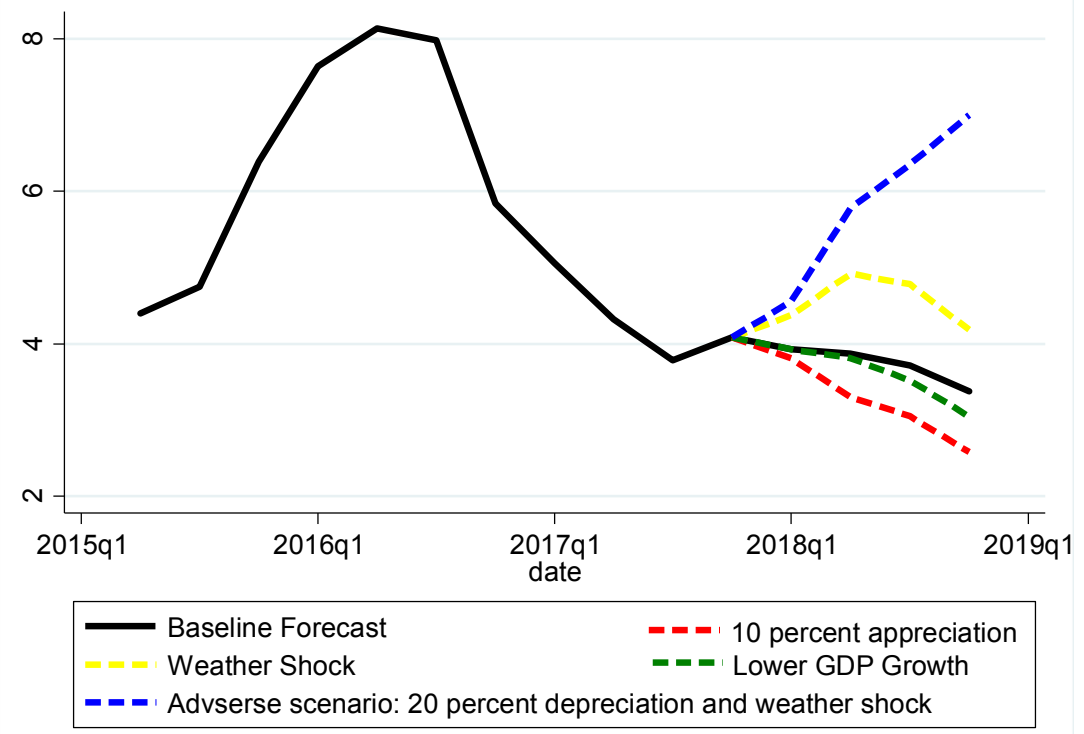




\section{b) Core Inflation}

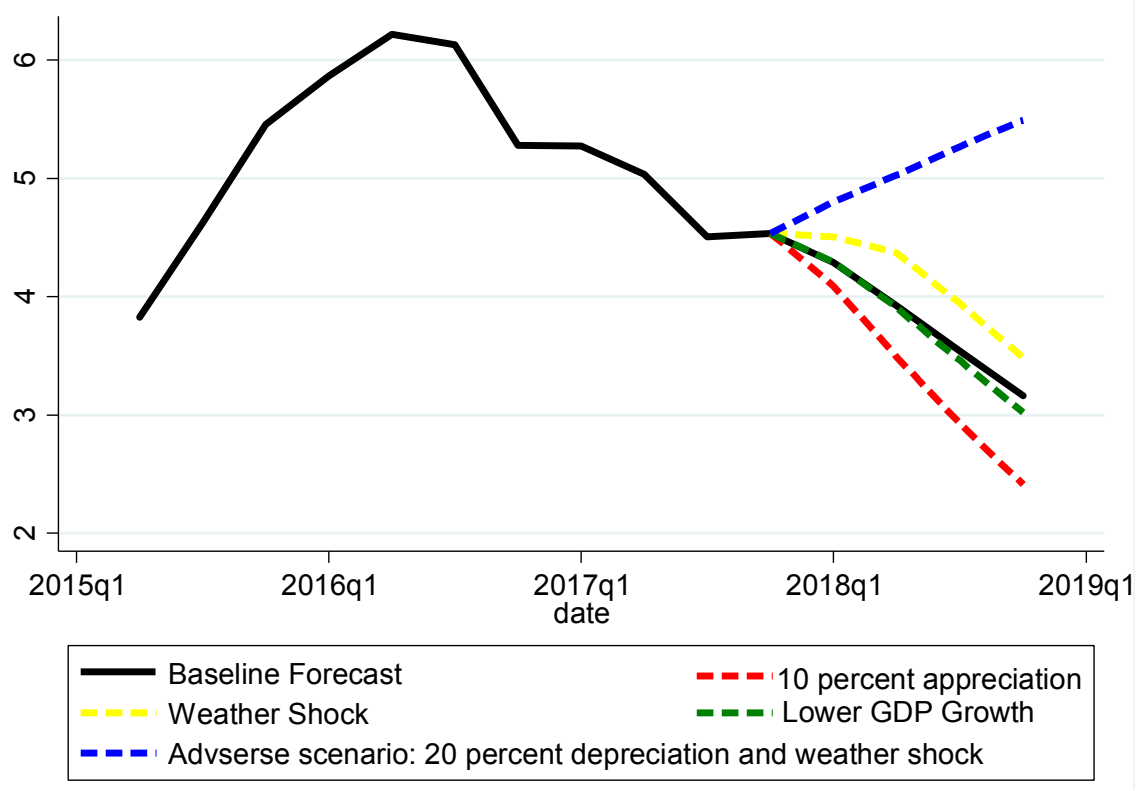

\section{Conclusion}

Inflation in Colombia has been coming down steadily since exchange rate depreciation and food price shocks pushed it well above the target in 2016. Tradable and food inflation fell fast as the shocks dissipated but core and non-tradable inflation remained higher. Understanding the dynamics of the subcomponents of inflation is important to form a view of how headline inflation is likely to evolve and thus to decide on the adequate monetary policy stance.

We explore the determinants of several subcomponents of inflation using the triangle model of the Phillips curve. The approach is essentially an auto-regressive distributed lag model including the output gap to capture demand shocks, lagged inflation to account for inertia, inflation expectations to capture the forward-looking component of inflation, and variables to proxy for supply shocks. Given that Colombia is a small open economy we include international prices and the exchange rate too. We adopt a systematic approach for lag length selection based on the Bayesian information criterion.

An initial top-down analysis of headline inflation shows that inertia is very high in Colombia. Exchange rate depreciation and world inflation affect inflation with the expected signs, as do inflation expectations. The coefficient on the output gap is positive for both headline and core inflation. The impact effect of an output gap shock on headline inflation is 0.1 and the long run impact is at least 0.5 .

In the analysis of the subcomponents of inflation, the bottom-up approach, we find an important role for supply-side shocks such as El Nino, the VAT hike, or world inflation. This is especially the case for tradable and food inflation. Rent and education inflation are 
strongly influenced by inertia and indexation. Regulated prices follow very idiosyncratic processes related to pricing formulas.

In pseudo out-of-sample forecasts, the combination of Phillips curves for each subcomponent of inflation beats the top-down Phillips curve and a benchmark AR process. Using the IMF WEO global assumptions and Colombia projections, the model forecasts headline inflation to fall towards 3 percent in 2018Q4. Sensitivity analysis shows that output gap shocks would have a moderate effect on inflation but negative supply shocks could push inflation substantially above the target. 


\section{Annex I. Additional Tables}

Annex Table 1. Statistics for Core Inflation Components

\begin{tabular}{lcccc}
\hline Tradeable & Sum(Coeff) & Lags & Joint F-Stat & Joint Prob F \\
\hline Tradeable Inflation & 0.86 & 4 & 810.43 & $0^{* * *}$ \\
Output Gap & 0.10 & 0 & 4.92 & $0.0309^{* *}$ \\
Nominal Effective Exchange Rate (Diff) & -0.04 & 0 & 34.72 & $0 * * *$ \\
El Niño & 0.35 & 0 & 3.72 & $0.0593^{*}$ \\
2yr Inflation Expectations & 0.17 & 0 & 2.15 & 0.148 \\
VAT & 1.54 & 0 & 11.09 & $0.0016^{* * *}$ \\
\hline
\end{tabular}

\begin{tabular}{lcccc} 
Non-Tradeable (Excluding Rent \& Edu.) & Sum(Coeff) & Lags & Joint F-Stat & Joint Prob F \\
\hline Non-Tradeable Inflation & 0.796 & 4 & 90.48 & $0^{* * *}$ \\
Output Gap & 0.076 & 0 & 1.22 & 0.2749 \\
Nominal Effective Exchange Rate (Diff) & 0.002 & 0 & 0.04 & 0.8366 \\
Inflation from Last Q4 & 0.097 & 0 & 1.85 & 0.1797 \\
\hline
\end{tabular}

\begin{tabular}{lcccc} 
Rent & Sum(Coeff) & Lags & Joint F-Stat & Joint Prob F \\
\hline Rent Inflation & 0.790 & 4 & 259.29 & $0 * * *$ \\
Output Gap & -0.004 & 0 & 0.03 & 0.874 \\
Nominal Effective Exchange Rate (Diff) & -0.002 & 0 & 0.52 & 0.475 \\
New Home Index & -0.002 & 2 & 1.7 & 0.1987 \\
Inflation from Last Q4 & 0.060 & 0 & 4.33 & $0.0428^{* *}$ \\
Trade Partner Weighted CPI & 0.078 & 0 & 4.61 & $0.0367^{* *}$ \\
El Niño & 0.160 & 0 & 2.95 & $0.0923^{*}$ \\
Cost Push Shock & 0.091 & 0 & 1.63 & 0.2075 \\
\hline
\end{tabular}

\begin{tabular}{lcccc} 
Education & Sum(Coeff) & Lags & Joint F-Stat & Joint Prob F \\
\hline Education Inflation & 0.675 & 4 & 167.98 & $0 * * *$ \\
Output Gap & 0.055 & 1 & 1.29 & 0.2614 \\
Nominal Effective Exchange Rate (Diff) & 0.000 & 0 & 0 & 0.9787 \\
Inflation from Last Q4 & 0.154 & 0 & 12.65 & $0.0008^{* * *}$ \\
VAT & 0.686 & 0 & 2.67 & 0.1082 \\
El Niño & -0.243 & 0 & 2.2 & 0.1444 \\
2yr Inflation Expectations & -0.296 & 0 & 7.11 & $0.0102^{* *}$ \\
\hline
\end{tabular}

\begin{tabular}{lcccc} 
Core Market Determined Prices & Sum(Coeff) & Lags & Joint F-Stat & Joint Prob F \\
\hline Core Market Determined Inflation & 0.871 & 4 & 812.82 & $0^{* * *}$ \\
Output Gap & 0.096 & 0 & 5.69 & $0.0207^{* *}$ \\
Nominal Effective Exchange Rate (Diff) & -0.033 & 0 & 34.29 & $0^{* * *}$ \\
EI Niño & 0.275 & 0 & 2.96 & $0.0914^{*}$ \\
VAT & 1.100 & 0 & 7.38 & $0.0089^{* * *}$ \\
2yr Inflation Expectations & 0.135 & 0 & 2.43 & 0.1246 \\
\hline
\end{tabular}


Annex Table 2. Statistics for Non-Core Inflation Components

\begin{tabular}{lcccc}
\hline Food & Sum(Coeff) & Lags & Joint F-Stat & Joint Prob F \\
\hline Food Inflation & 0.679 & 4 & 85.74 & $0^{* * *}$ \\
Output Gap & 0.341 & 0 & 4.25 & $0.0445^{* *}$ \\
Nominal Effective Exchange Rate (Diff) & -0.061 & 3 & 4.21 & $0.0454^{* *}$ \\
Trade Partner Weighted CPI & 0.642 & 0 & 6.31 & $0.0153^{* *}$ \\
El Niño & 1.055 & 0 & 3.19 & $0.0801^{*}$ \\
2yr Inflation Expectations & 0.457 & 0 & 3.33 & $0.0742^{*}$ \\
\hline
\end{tabular}

Public Services

Public Services Inflation

El Niño

Inflation from Last Q4

Fuel

Fuel Inflation

Gulf Oil Price Growth

VAT

Inflation from Last Q4

Transportation

Transportation Inflation

Inflation from Last Q4
Sum(Coeff) Lags

Joint F-Stat Joint Prob F

0.829

0.197

4

1

34.25

$0 * * *$

1

3.33

0.666
2.130
0.157

Sum(Coeff)

Lags

Joint F-Stat Joint Prob F

\begin{tabular}{ccc}
4 & 0.33 & 0.5763 \\
4 & 35.9 & $0.0001^{* * *}$ \\
2 & 16.83 & $0.0015^{* * *}$ \\
1 & 2.66 & 0.1288 \\
\hline
\end{tabular}




\section{References}

Abdih, Y. R. Balakrishnan and B. Shang (2016), "What is Keeping Inflation Low: Insights from a Bottom-Up Approach," IMF Working Paper No. 16/124 (Washington: International Monetary Fund).

Aron, J. K. Creamer, J. Muellbauer and N. Rankin (2014), "Exchange Rate Pass-Through to Consumer Prices in South Africa: Evidence from Micro-Data," The Journal of Development Studies, No. 50:1.

Blanchard, O., E. Cerutti and L. Summers (2015), "Inflation and Activity - Two Explorations and their Monetary Policy Implications" IMF Working Paper No. 15/230 (Washington: International Monetary Fund).

Bryan, M.F. and B. Meyer (2010), "Are Some Prices in the CPI More Forward Looking than Others? We Think So.," Economic Commentary, No. 2010-2.

Bunn and Ellis (2012), "Examining the Behaviour Of Individual U.K. Consumer Prices," The Economic Journal, Vol. 122, Issue 558.

R. J. Gordon (2011), "The History of the Phillips Curve: Consensus and Bifurcation," Economica, Vol.78, No. 309.

International Monetary Fund (2016), "Subdued Demand: Symptoms and Remedies" World Economic Outlook, October.

Julio, J.M., H.M. Zarate and M.D. Hernandez (2010), “The Stickiness of Colombian Consumer Prices," Ensayos sobre politica economica, Vol. 28, No. 63.

Julio J. M., J.G. Gomez and M.D. Hernandez. (2017), "La inflacion de los precios rigidos en Colombia,” Banco de la Republica, Borradores de Economia, No. 1007.

Lopes, E.E. and M.A. Misas (1999), "Un Examen Empirico de la Curva de Phillips in Colombia," Banco de la Republica, Borradores de Economia, No. 117.

Matheson, T. (2006), "Phillips Curve Forecasting in a Small Open Economy," Reserve Bank of New Zealand, Discussion Paper Series, DP2006/01. 